\title{
Systematic review and meta-analysis of diagnostic studies of proximal surface caries
}

\author{
Mila Janjic Rankovic ${ }^{1} \cdot$ Svetlana Kapor ${ }^{2} \cdot$ Yegane Khazaei $^{2,3} \cdot$ Alexander Crispin $^{3} \cdot$ Ina Schüler $^{4} \cdot$ Felix Krause $^{5}$. \\ Kim Ekstrand ${ }^{6} \cdot$ Stavroula Michou $^{6} \cdot$ Florin Eggmann $^{7} \cdot$ Adrian Lussi $^{8,9} \cdot$ Marie-Charlotte Huysmans $^{10}$. \\ Klaus Neuhaus ${ }^{7,11} \cdot$ Jan Kühnisch ${ }^{2,12}$ (1)
}

Received: 7 September 2020 / Accepted: 29 July 2021 / Published online: 4 September 2021

(c) The Author(s) 2021

\begin{abstract}
Aim This systematic review and meta-analysis aimed to assess the diagnostic accuracy and reliability of commonly used caries detection methods for proximal caries diagnostics. Visual examination (VE), bitewing radiography (BWR), laser fluorescence (LF), and fibre-optic transillumination (FOTI) were considered in detail.

Material and methods PRISMA guidelines for the reporting of systematic reviews and meta-analyses were applied. The mnemonic PIRDS (problem, index test, reference test, diagnostic and study type) concept was used to guide the literature search. Next, studies that met the inclusion criteria were stepwise selected and evaluated for their quality with a risk of bias (RoB) assessment tool. Studies with low/moderate bias and sufficient reporting were considered for meta-analysis. The pooled sensitivity (SE), specificity (SP), diagnostic odds ratio (DOR), and area under the ROC curve (AUC) were calculated. Results From 129 studies meeting the selection criteria, 31 in vitro studies and five clinical studies were finally included in the meta-analysis. The AUC values for in vitro VE amounted to 0.84 (caries detection) and 0.85 (dentin caries detection). BWR ranged in vitro from 0.55 to 0.82 (caries detection) and 0.81-0.92 (dentin caries detection). LF showed higher AUC values for overall caries detection (0.91) and dentin caries detection (0.83) than did other methods. Clinical data are limited. Conclusion The number of diagnostic studies with low/moderate RoB was found to be low and indicates a need for highquality, well-designed caries diagnostic studies.

Clinical relevance BWR and LF showed good diagnostic performance on proximal surfaces. However, because of the low number of includable clinical studies, these data should be interpreted with caution.
\end{abstract}

Keywords Approximal caries · Proximal caries · Interproximal caries $\cdot$ Caries detection $\cdot$ Caries diagnostics · Visual examination $\cdot$ Bitewing radiography $\cdot$ Laser fluorescence measurements $\cdot$ Fibre-optic transillumination $\cdot$ Systematic review $\cdot$ Meta-analysis $\cdot$ Diagnostic performance $\cdot$ Diagnostic accuracy $\cdot$ Sensitivity $\cdot$ Specificity

\section{Introduction}

Many studies have indicated a decline in caries prevalence $[1,2]$. However, the occurrence of proximal caries lesions in posterior teeth is still very common in primary and permanent dentition and should not be underestimated [3]. For this reason, the detection, assessment, and diagnostics of proximal caries lesions is an important procedure for clinicians in daily dental practice and should enable well-justified preventive, non-operative, or operative caries management

Jan Kühnisch

jkuehn@dent.med.uni-muenchen.de

Extended author information available on the last page of the article
[4-6]. When considering visual examination (VE) as a basic diagnostic method, it must be concluded that this technique is generally insufficient to estimate lesional characteristics in terms of detecting early lesions and determining the caries extent or activity at proximal sites [7-11]. Therefore, conventional, film-based bitewing radiographs (conv-BWR) were introduced as an additional diagnostic method of first choice several decades ago [12] and are still used mostly through digital bitewing radiography (dig-BWR) in daily clinical routines $[13,14]$. To improve the repeatability of diagnostic examinations and provide $\mathrm{X}$-ray-free diagnostics, several other photo-optical methods have been introduced over the last few decades, and these modalities, e.g. laser fluorescence (LF, DIAGNOdent, KaVo, Biberach, Germany) 
or fibre-optic transillumination (FOTI), can potentially be used on proximal sites [14-16].

Over the past decades, many in vitro and in vivo studies on proximal caries have assessed the diagnostic performance of the abovementioned methods. Meanwhile, systematic reviews have summarised the existing data [13, 16-23]. However, when analysing these studies in detail, it becomes evident that there is considerable variation in the results, which is probably linked to variations in the chosen methodology, e.g. different study aims, differences in the usage of the index and reference test method, different thresholds to determine the caries process or technical differences in the performance of each study. All of these aspects might limit the comparability between the studies. Even though the available systematic reviews $[13,17,18]$ have mentioned substantial heterogeneity between the included diagnostic studies, little attention has been paid to this important methodological issue so far, and therefore, potential methodological sources of bias might be undetected and may also potentially skew the meta-analytic data. Ideally, each diagnostic trial should be designed similarly according to equal scientific standards and protocols to generate comparable results and, therefore, decrease the potential risk of bias (RoB) and exhibit low heterogeneity.

Therefore, the primary objective of this report was to assess and compare the diagnostic performance of commonly used methods for proximal caries detection under in vitro and in vivo conditions in permanent, posterior teeth. To achieve this aim, it was necessary first to identify relevant studies on the basis of a systematic search of the literature, second, to evaluate potential sources of bias, and third, to provide meta-analytic data of the diagnostic accuracy.

\section{Material and methods}

To support the unbiased inclusion of studies and reporting of findings, this systematic review was conducted according to the PRISMA-DTA statement (Preferred Reporting Items for a Systematic Review and Meta-Analyses of Diagnostic Test Accuracy Studies) [24]. Additionally, most recently published drafts of the "Cochrane Handbook for Diagnostic Test Accuracy Reviews" [25] and "The Joanna Briggs Institute Reviewers' Manual 2015: Methodology for JBI Scoping Reviews" [26] influenced this work. The systematic review was registered on the PROSPERO platform (CRD42017069894).

Inclusion and exclusion criteria Studies eligible for inclusion were in vivo and in vitro caries diagnostic studies that tested the diagnostic performance of the following caries diagnostic methods: (1) VE with and without tactile examination, (2) conventional bitewing radiography (conv-BWR) independently from the film type used, (3) digital bitewing radiography (dig-BWR), (4) laser fluorescence measurement (LF, DIAGNOdent 2095 and 2190; KaVo, Biberach, Germany), and (5) fibre-optic transillumination with (FOTI, I.C. Lercher, Emmingen, Germany). Only studies assessing primary caries on the proximal surfaces of permanent posterior teeth were considered for inclusion. Studies containing information on primary teeth or teeth with restorations, secondary caries, or artificially induced caries lesions were excluded. The actual status of the tooth surface had to be confirmed by a suitable reference test. In in vitro studies, histological validation of dental tissues was considered the "gold standard," while in in vivo studies, this validation was direct VE after tooth separation or "bioptical" cavity preparation. In order to be included, at least one of the following outcomes had to be assessed: diagnostic test accuracy (expressed in terms of sensitivity (SE), specificity (SP), AZ values from ROC curves, and/or reliability/reproducibility (Kappa). Only studies published in English until 31 December 2018 were considered for inclusion.

Development of the search strategy In relation to the aboveformulated research question and the corresponding inclusion and exclusion criteria, a structured search of the literature was initiated in accordance with the mnemonic PIRD recommendations [27]. The final consented search items are shown in Table 1.

Literature search and study selection process A literature search was performed in the MEDLINE (PubMed) and EMBASE databases following the predefined search strategy (Figs. 1, Table 1). The electronic search yielded 721 abstracts from PubMed and 711 abstracts from EMBASE. Both sets of records were downloaded from each database to the bibliographic software package EndNote X7 (Clarivate Analytics, Philadelphia, PA, USA) and merged into one core database to remove duplicate records and to facilitate retrieval of relevant articles. All potentially relevant reports identified after searching other nonelectronic sources were entered into EndNote manually. After the elimination of duplicates, 851 studies were identified. Additionally, five new studies were identified through other sources (Fig. 1).

The titles and abstracts of all identified studies were examined by two reviewers independently (M.J.R and S.K.), according to predefined inclusion and exclusion criteria. Review authors were not blinded to the names of the authors, institutions, journal of publication, or results of the studies. All records identified by the searches were primarily checked on the basis of the title and abstract. Records that were obviously irrelevant were excluded, and the full text of all remaining records was obtained. If the relevant information for meeting the inclusion criteria was not available from the abstract and/or title, we obtained the full text 
Table 1 Search strategy and documentation of keywords according to the PIRDS concept [27]

\begin{tabular}{|c|c|c|c|c|c|}
\hline \multicolumn{2}{|l|}{ Population/Problem $(P)$} & \multicolumn{2}{|l|}{ Index test $(I)$} & Reference test $(R)$ & \\
\hline $\begin{array}{l}\text { caries } \\
\text { decay } \\
\text { AND } \\
\text { proximal } \\
\text { approximal interdental }\end{array}$ & AND & $\begin{array}{l}\text { visual } \\
\text { clinical* } \\
\text { inspect* } \\
\text { ICDAS } \\
\text { bitewing } \\
\text { conventional } \\
\text { digital } \\
\text { film } \\
\text { radiogra* } \\
\text { analo* } \\
\text { speed* } \\
\text { X ray } \\
\text { Xray } \\
\text { radiol* } \\
\text { roentge* } \\
\text { laser } \\
\text { fluorescence } \\
\text { diagnodent } \\
\text { foti } \\
\text { difoti } \\
\text { fiber } \\
\text { fibre } \\
\text { transillumination } \\
\text { opti* } \\
\text { qlf } \\
\text { quantit* } \\
\text { laser } \\
\text { light } \\
\text { induced }\end{array}$ & AND & $\begin{array}{l}\text { valid* } \\
\text { accuracy } \\
\text { sensitivity } \\
\text { specificity } \\
\text { SE } \\
\text { SP } \\
\text { ROC } \\
\text { Az } \\
\text { reproducib* } \\
\text { reliab* } \\
\text { Kappa } \\
\text { threshold } \\
\text { cut-off } \\
\text { performance } \\
\text { histolog* } \\
\text { micro } \\
\text { micro computed } \\
\text { CT } \\
\text { *CT }\end{array}$ & $\begin{array}{l}\text { Systemat* } \\
\text { Meta-Analysis } \\
\text { Diagnos* } \\
\text { Detect* } \\
\text { Assessm* } \\
\text { Vivo } \\
\text { Vitro } \\
\text { Study } \\
\text { Studies }\end{array}$ \\
\hline \multicolumn{6}{|c|}{$\begin{array}{l}\text { MeSH terms that were used to search the PubMed and EMBASE databases: } \\
\text { ((caries OR decay) AND (proximal OR approximal OR interdental) AND (visual OR clinical* OR inspect* OR icdas OR bitewing OR con- } \\
\text { ventional OR digital OR film OR radiogra* OR analo* OR speed* OR X ray OR Xray OR radiol* OR roentge* OR laser OR fluorescence } \\
\text { OR diagnodent OR foti OR difoti OR fiber OR fibre OR transillumination OR opti* OR qlf OR quantit* OR laser OR light OR induced) } \\
\text { AND (OR valid* OR accuracy OR sensitivity OR specificity OR se OR sp OR roc OR az OR reproducib* OR reliab* OR kappa OR thresh- } \\
\text { old OR cutoff OR perfORmance OR histolog* OR micro OR micro computed OR ct OR *ct) AND (systemat* OR review OR meta-analysis } \\
\text { OR diagnos* OR detect* OR assessm* OR vivo OR vitro OR study OR studies)) }\end{array}$} \\
\hline
\end{tabular}

of the report. In this way, 204 studies were selected for fulltext reading and were assessed independently by the same two reviewers. Any doubts or disagreements were solved by discussion with an experienced researcher (J.K.). Articles that did not meet all inclusion criteria after the full-text assessment $(N=75)$ were excluded from further examination. Reasons for their exclusion were recorded in specially prepared tables (Supplemental Table S0). Figure 1 depicts and summarises the complete study selection process.

Data extraction Data from the included studies were extracted by both reviewers (M.J.R. and S.K.) using a structured examination form. Any disagreements were resolved through discussion with an expert (J.K.) until a consensus was reached. Trial authors were contacted for clarification or missing information, where necessary. In brief, the following information was extracted from the papers: (1) the setting of in vivo or in vitro studies; (2) study material details, including the number of patients, age, type, and the number of teeth used in the investigation; (3) diagnostic criteria and methodology of the index and reference standard including cutoff values (Supplementary Table S1a-e); and (4) diagnostic-accuracy results (SE, SP, Az value, inter- and, intraexaminer reliability). All extracted data are summarised in tables and can be obtained from the supplementary online content on the journal website (Supplementary Tables S3ad, S4a-d, S5a-d, S6a-d, and S7a-d).

RoB assessment and study selection for meta-analysis For this study project, a new, tailor-made RoB assessment tool was used (Supplementary Table S2). Briefly, the tool consists of four domains, each of them containing items that cover different sources of bias. To determine the RoB in the primary studies, one of three modalities was used, high, low, or unclear. The category "unclear RoB" was used whenever no information or insufficient details were reported by the study group. The RoB assessment was performed independently by two reviewers (M.J.R., S.K.). An additional 
Fig. 1 Flow diagram detailing our search and study selection process applied during the systematic literature search (1st step) and study quality assessment (2nd step)

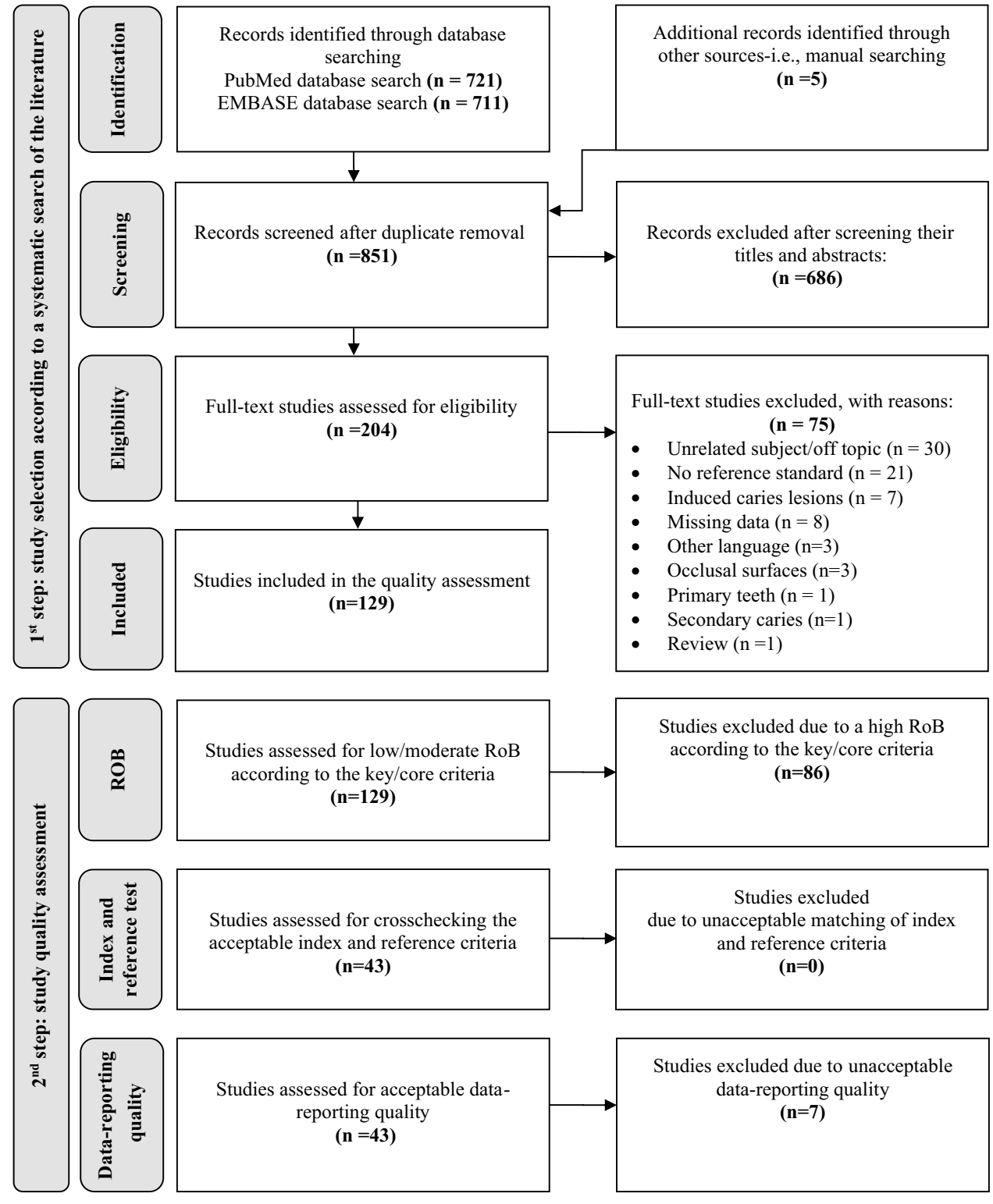

Studies included in the quantitative synthesis meta-analysis $(n=36)$ in vitro $(n=31)$ and in vivo $(n=5)$ reassessment was performed by two other colleagues from the workgroup (I.S., F.K.).

To choose studies with a low RoB for the meta-analysis, an additional selection step was performed by checking the study quality. Studies that were found to be related to a low/ moderate RoB in the key items (index test criteria, reference test criteria, incorporation bias, partial verification bias, and differential verification bias) were included in the meta-analysis. In the case of in vivo studies, differential verification bias was not considered a key item, since using two different reference tests for different caries thresholds can be justified for ethical reasons (e.g. "bioptical" cavity preparation not applicable in all cases). In a second selection step, each study report was carefully cross-checked again if the index and reference test criteria and the corresponding thresholds were correctly used. The final inclusion was made when the quality of data reporting was found to be sufficient. At least $2 \times 2$ contingency tables or the SE, SP, negative predictive value (NPV), and positive predictive value (PPV), which could be used in the meta-analysis, had to be reported. The RoB assessment of all systematically searched and selected studies was performed independently by 2 reviewers (M.J.R and S.K.); discrepancies were resolved again in cooperation with an experienced researcher (J.K.). 
A) RISK OF BIAS GRAPH FOR IN VIVO CARIES DIAGNOSIS STUDIES

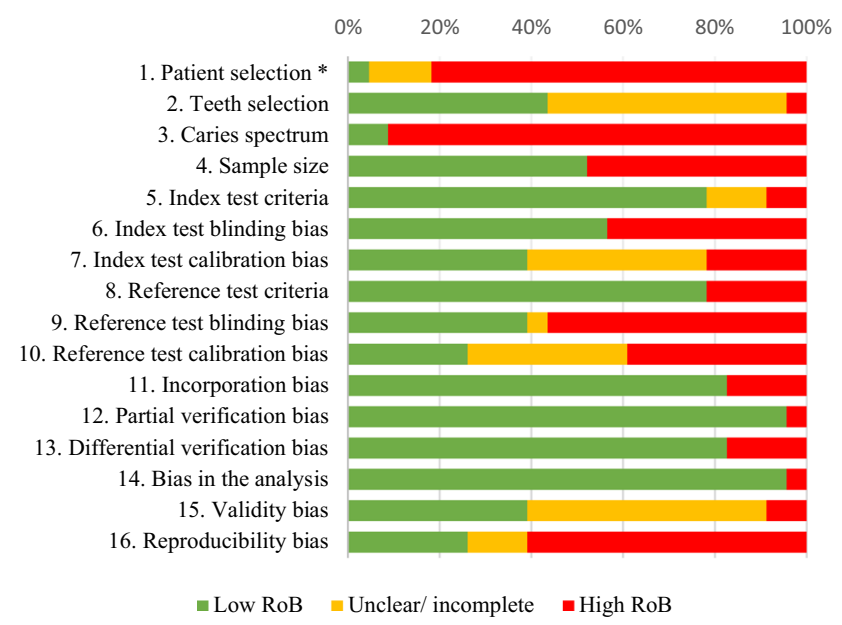

\section{B) RISK OF BIAS GRAPH FOR IN VITRO CARIES DIAGNOSTIC STUDIES}

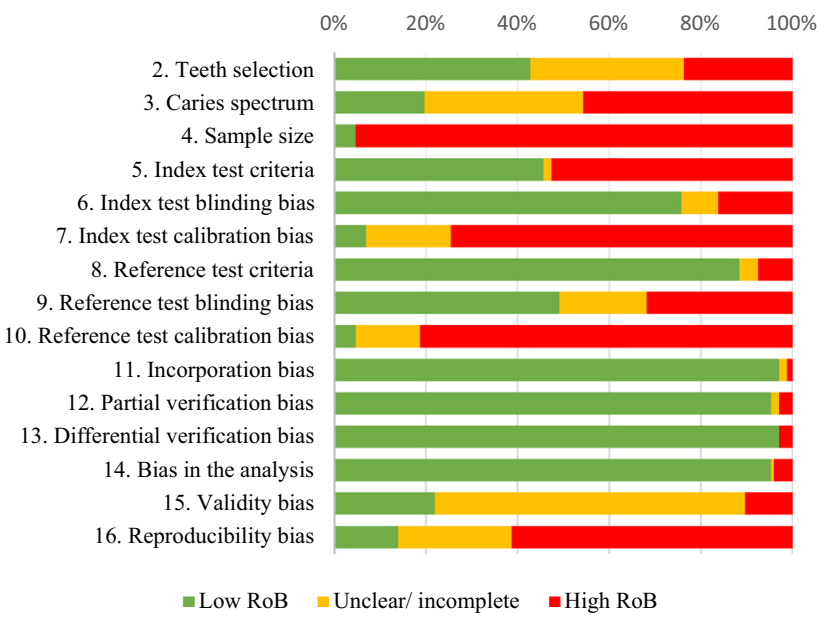

Fig. 2 RoB graph across included in vivo (a) and in vitro (b) caries diagnostic studies for proximal surfaces. *Item no. 1 (patient selection bias) is only available for clinical diagnostic studies

Data handling, statistical procedures, and meta-analysis All data were entered into a database and later transferred to Excel spreadsheets (Excel 2010, Microsoft Corporation, Redmond, WA, USA). Descriptive data analyses were performed using Microsoft Excel 2010 and the statistical package mada version 0.5.9. [28] for RStudio [29]. If the included studies provided contingency tables, the data were used directly. If not, we calculated true positives (SE), true negatives (SP), false positives, and false negatives from the given data in the original publication. If these calculations were not possible, the corresponding study was excluded. Corrections of tables with zero cells were also made; when, for example, TP is zero, $\mathrm{R}$ itself makes a correction by changing the zero to 0.5 (a very small number) because RStudio cannot deal with zero cells. In some reports, statistical information was given to more than one examiner. However, in those cases, a mean was calculated by logit transformation.

Meta-analytic statistics were calculated for all included diagnostic test methods and commonly used diagnostic thresholds. Diagnostic accuracy and their 95\% confidence intervals $(95 \% \mathrm{CI})$ were calculated from the pooled data of all included studies, in terms of SE, SP, and the diagnostic odds ratio (DOR). A bivariate diagnostic random-effects meta-analysis suggested by Reitsma et al. [30] was used to provide pooled estimates of SE and SP for the respective subgroups along with their $95 \% \mathrm{CI}$. This method can take the heterogeneity between studies into account by jointly analysing the logit transformation of SEs and SPs [31]. Finally, the pooled DOR was calculated using a randomeffects model following the approach by DerSimonian and Laird and aimed at describing the performance of the included diagnostic tests [32]. An uninformative test shows a DOR value of 1; as the DOR increases, the test has more discriminatory power [33]. The area under the curve (AUC) of summary receiver operating characteristics (sROC) was reported to create an overall view of the results within each subgroup. The AUC value quantifies the overall ability of a diagnostic test to discriminate between individuals with the disease and those without the disease [34]. The ideal test would have an AUC value of 1, whereas a random guess would have an AUC of 0.5; the larger the area under the ROC curve, the more accurate the diagnostic test [33]. In addition, sROC plots and forest plots were computed to illustrate the diagnostic performance and heterogeneity, respectively [34].

\section{Results}

Altogether, 129 studies were accounted for after meeting the inclusion criteria in the first selection step (Fig. 1, Table 2); 120 were performed under in vitro conditions and 9 under in vivo conditions. When additionally considering those studies with a low/moderate RoB (Fig. 2), the number of includable studies decreased to 43 . Furthermore, 7 studies had to be excluded due to the low quality of data reporting. Finally, 31 laboratory studies [35-65] and five clinical studies [66-70] were included in the meta-analysis. Figure 1 and Table 2 provide a summary of the step-by-step selection process. All details of the systematic search of the literature and the stepwise selection process before meta-analysis can be taken from the supplementary online content. 
Table 2 Overview of the identified diagnostic studies in relation to the method used and characteristics of the study setup with stepwise included studies for meta-analysis

\begin{tabular}{|c|c|c|c|c|c|}
\hline \multirow[t]{3}{*}{ Studies on diagnostic methods } & \multicolumn{2}{|l|}{ 1st step } & \multicolumn{3}{|l|}{ 2nd step } \\
\hline & \multicolumn{2}{|c|}{$\begin{array}{l}\text { Study inclusion according to the systematic search of } \\
\text { the literature }\end{array}$} & \multicolumn{3}{|c|}{$\begin{array}{l}\text { Study inclusion according to the quality assess- } \\
\text { ment }\end{array}$} \\
\hline & Study setup & $\begin{array}{l}\text { Specification ( } N \text { according to } \\
\text { PRISMA) }\end{array}$ & $\begin{array}{l}\text { Low/ } \\
\text { moderate } \\
\text { RoB }\end{array}$ & $\begin{array}{l}\text { Acceptable index } \\
\text { and reference test }\end{array}$ & $\begin{array}{l}\text { Acceptable data } \\
\text { reporting quality }\end{array}$ \\
\hline \multirow[t]{2}{*}{$\operatorname{VE}(N=20)$} & \multicolumn{2}{|l|}{ In vitro $(N=15)$} & 10 & 10 & 10 \\
\hline & \multicolumn{2}{|l|}{ In vivo $(N=5)$} & 2 & 2 & 2 \\
\hline \multirow{7}{*}{$\begin{array}{l}\text { Conventional bitewing radiography } \\
(N=77)\end{array}$} & \multirow{4}{*}{ In vitro $(N=72)$} & D-speed $(N=17)$ & 24 & 24 & 19 \\
\hline & & E-speed $(N=43)$ & & & \\
\hline & & F-speed $(N=26)$ & & & \\
\hline & & Not specified $(N=4)$ & & & \\
\hline & \multirow[t]{3}{*}{ In vivo $(N=5)$} & D-speed $(N=0)$ & & & \\
\hline & & E-speed $(N=5)$ & 1 & 1 & 1 \\
\hline & & F-speed $(N=0)$ & & & \\
\hline \multirow{4}{*}{$\begin{array}{l}\text { Digital bitewing radiography } \\
(N=88)\end{array}$} & \multirow[t]{2}{*}{ In vitro $(N=81)$} & Phosphor plate $(N=46)$ & 23 & 23 & 19 \\
\hline & & Sensor $(N=48)$ & & & \\
\hline & \multirow[t]{2}{*}{ In vivo $(N=7)$} & Phosphor plate $(N=3)$ & 4 & 4 & 3 \\
\hline & & Sensor $(N=4)$ & & & \\
\hline \multirow[t]{4}{*}{ LF measurement $(N=9)$} & \multirow[t]{2}{*}{ In vitro $(N=5)$} & DIAGNOdent $2095(N=1)$ & 5 & 5 & 4 \\
\hline & & DIAGNOdent 2190/pen $(N=4)$ & & & \\
\hline & \multirow[t]{2}{*}{ In vivo $(N=4)$} & DIAGNOdent $2095(N=0)$ & 4 & 4 & 4 \\
\hline & & DIAGNOdent 2190/pen $(N=4)$ & & & \\
\hline \multirow[t]{2}{*}{ Fibre-optic transillumination $(N=7)$} & In vitro $(N=4)$ & - & - & - & \\
\hline & In vivo $(N=3)$ & - & - & - & \\
\hline
\end{tabular}

The majority of the included studies assessed the diagnostic accuracy of conventional and digital BWR, and only a few of them additionally assessed VE and LF (Table 2). Table 3 provides an overview of the meta-analytic diagnostic accuracy for each diagnostic method, diagnostic threshold, and study setting. The results from the clinical studies are partial and mostly limited to the dentin detection level, showing only data based on a few studies. According to this assessment, digital, sensor-based BWR showed the highest SE value for dentin detection level, of 0.96 , followed by phosphor plate-based BWR (0.83), LF (SE=0.63), E-speed BWR (0.35), and VE (SE=0.32) (Table 3).

Data from the laboratory settings are based on the findings from a greater number of studies and, therefore, are more complete. The results from the bivariate diagnostic random-effects meta-analysis indicated that VE showed higher SE values for overall caries detection (0.64) and 1/3 dentin caries detection (0.93), while for dentin caries detection it was only 0.09. Contrary, SP for the dentine caries detection threshold was higher (0.99) than for overall caries detection (0.85) and $1 / 3$ dentin caries detection thresholds (0.84). AUC values ranged from 0.84 to 0.95 for $\mathrm{VE}$ under in vitro conditions.
Among conv-BWR modalities, F-speed showed the highest SE (0.43) for the caries detection level and E-speed (0.67) for dentin caries detection. SP was high for both caries detection levels, ranging from 0.88 to 0.99 between the different modalities. The AUC values were lower for any type of caries detection level in comparison to the dentin caries detection level and ranged from 0.55 to 0.92 . In general, the results for digital BWR were in the same order of magnitude, with exception of higher SE for phosphor plate-based BWR; the AUC values ranged between 0.74 and 0.92 . The bivariate diagnostic random-effects meta-analysis showed a good diagnostic performance for LF on proximal sites in comparison to all other caries diagnostic methods irrespective of the cutoff level used; the documented AUC values ranged above 0.83 . sROC plots and forest plots can be found in the supplemental online content.

\section{Discussion}

In the case of proximal caries lesions, where direct VE is mostly impossible, the use of additional caries detection and diagnostic methods is typically indicated. During previous 
Table 3 Bivariate diagnostic random-effects meta-analysis for the finally included in vitro and in vivo studies for all diagnostic methods at different caries detection levels

\begin{tabular}{|c|c|c|c|c|c|c|}
\hline \multicolumn{2}{|c|}{ Method and parameters } & \multicolumn{2}{|c|}{ Caries detection level } & \multicolumn{2}{|c|}{ Dentin detection level } & \multirow{2}{*}{$\begin{array}{l}1 / 3 \text { dentin detection } \\
\text { level } \\
\text { In vitro }\end{array}$} \\
\hline & & In vitro & In vivo & In vitro & In vivo & \\
\hline Visual examination & $\begin{array}{l}N \\
\text { SE }(95 \% \mathrm{CI}) \\
\text { SP }(95 \% \mathrm{CI}) \\
\text { DOR }(95 \% \mathrm{CI}) \\
\text { AUC }\end{array}$ & $\begin{array}{l}9 \\
0.64(0.42-0.81) \\
0.85(0.74-0.92) \\
11.49(5.19-25.46) \\
0.84\end{array}$ & - & $\begin{array}{l}1 \\
0.09(0.04-0.24) \\
0.99(0.94-0.999) \\
13.26(1.44- \\
122.51) \\
0.85\end{array}$ & $\begin{array}{l}2 \\
0.32(0.07-0.74) \\
0.76(0.11-0.99) \\
1.84(0.03-103.47) \\
0.53\end{array}$ & $\begin{array}{l}1 \\
0.93(0.77-0.98) \\
0.84(0.76-0.89) \\
67.0(14.7-304.9) \\
0.95\end{array}$ \\
\hline $\begin{array}{l}\text { Conventional bite- } \\
\text { wing radiography } \\
\text { (D-speed) }\end{array}$ & $\begin{array}{l}N \\
\text { SE }(95 \% \mathrm{CI}) \\
\text { SP }(95 \% \mathrm{CI}) \\
\text { DOR }(95 \% \mathrm{CI}) \\
\text { AUC }\end{array}$ & $\begin{array}{l}2 \\
0.19(0.13-0.28) \\
0.96(0.91-0.99) \\
5.2(1.6-16.8) \\
0.55\end{array}$ & - & $\begin{array}{l}1 \\
0.17(0.07-0.40) \\
0.99(0.96-0.999) \\
31.0(3.3-291.3) \\
0.91\end{array}$ & - & - \\
\hline $\begin{array}{l}\text { Conventional bite- } \\
\text { wing radiography } \\
\text { (E-speed) }\end{array}$ & $\begin{array}{l}N \\
\text { SE }(95 \% \mathrm{CI}) \\
\text { SP }(95 \% \mathrm{CI}) \\
\text { DOR }(95 \% \mathrm{CI}) \\
\text { AUC }\end{array}$ & $\begin{array}{l}9 \\
0.42(0.28-0.57) \\
0.90(0.84-0.93) \\
6.80(4.58-10.10) \\
0.82\end{array}$ & - & $\begin{array}{l}5 \\
0.67(0.19-0.95) \\
0.94(0.71-0.99) \\
31.40(14.31- \\
68.93) \\
0.92\end{array}$ & $\begin{array}{l}1 \\
0.35(0.19-0.51) \\
0.91(0.80-0.96) \\
4.8(1.48-15.48) \\
0.74\end{array}$ & - \\
\hline $\begin{array}{l}\text { Conventional bite- } \\
\text { wing radiography } \\
\text { (F-speed) }\end{array}$ & $\begin{array}{l}N \\
\text { SE }(95 \% \mathrm{CI}) \\
\text { SP }(95 \% \mathrm{CI}) \\
\text { DOR }(95 \% \mathrm{CI}) \\
\text { AUC }\end{array}$ & $\begin{array}{l}8 \\
0.43(0.31-0.57) \\
0.88(0.74-0.95) \\
5.34(2.55-11.17) \\
0.72\end{array}$ & - & $\begin{array}{l}3 \\
0.42(0.29-0.56) \\
0.92(0.86-0.96) \\
8.7(4.2-18.1) \\
0.81\end{array}$ & - & $\begin{array}{l}1 \\
0.54(0.36-0.70) \\
0.996(0.96-1) \\
283.6(16.1-5010.0) \\
0.98\end{array}$ \\
\hline $\begin{array}{l}\text { Digital bitewing } \\
\text { radiography } \\
\text { (sensor) }\end{array}$ & $\begin{array}{l}N \\
\text { SE }(95 \% \mathrm{CI}) \\
\text { SP }(95 \% \mathrm{CI}) \\
\text { DOR }(95 \% \mathrm{CI}) \\
\text { AUC }\end{array}$ & $\begin{array}{l}12 \\
0.35(0.26-0.45) \\
0.90(0.85-0.93) \\
5.01(2.83-8.88) \\
0.74\end{array}$ & $\begin{array}{l}1 \\
0.55(0.42-0.67) \\
0.93(0.77-0.98) \\
17.11(3.73-78.39) \\
0.82\end{array}$ & $\begin{array}{l}4 \\
0.36(0.30-0.42) \\
0.95(0.93-0.97) \\
12.84(6.56-25.13) \\
0.90\end{array}$ & $\begin{array}{l}1 \\
0.96(0.91-0.98) \\
0.50(0.02-0.98) \\
24.4(0.44- \\
1359.98) \\
0.89\end{array}$ & - \\
\hline $\begin{array}{l}\text { Digital bitewing } \\
\text { radiography } \\
\text { (phosphor plate) }\end{array}$ & $\begin{array}{l}N \\
\text { SE }(95 \% \mathrm{CI}) \\
\text { SP }(95 \% \mathrm{CI}) \\
\text { DOR }(95 \% \mathrm{CI}) \\
\text { AUC }\end{array}$ & $\begin{array}{l}11 \\
0.41(0.25-0.61) \\
0.89(0.83-0.93) \\
5.56(3.04-10.16) \\
0.82\end{array}$ & - & $\begin{array}{l}2 \\
0.86(0.03-0.99) \\
0.86(0.11-0.99) \\
26.06(7.29-93.21) \\
0.92\end{array}$ & $\begin{array}{l}1 \\
0.83(0.77-0.88) \\
0.60(0.20-0.90) \\
7.5(1.19-47.13) \\
0.79\end{array}$ & - \\
\hline $\begin{array}{l}\text { Laser fluorescence } \\
2190\end{array}$ & $\begin{array}{l}N \\
\text { SE }(95 \% \mathrm{CI}) \\
\text { SP }(95 \% \mathrm{CI}) \\
\text { DOR }(95 \% \mathrm{CI}) \\
\text { AUC }\end{array}$ & $\begin{array}{l}5 \\
0.79(0.62-0.90) \\
0.89(0.76-0.95) \\
30.79(8.74- \\
\quad 108.51) \\
0.91\end{array}$ & $\begin{array}{l}1 \\
0.92(0.82-0.96) \\
0.90(0.73-0.97) \\
99(22.01-445.30) \\
0.96\end{array}$ & $\begin{array}{l}5 \\
0.82(0.58-0.94) \\
0.81(0.78-0.85) \\
23.09(7.01-76.04) \\
0.83\end{array}$ & $\begin{array}{l}3 \\
0.63(0.58-0.68) \\
0.60(0.15-0.93) \\
2.18(0.24-19.95) \\
0.63\end{array}$ & - \\
\hline $\begin{array}{l}\text { Fibre-optic transil- } \\
\text { lumination FOTI }\end{array}$ & $\begin{array}{l}N \\
\text { SE }(95 \% \mathrm{CI}) \\
\text { SP }(95 \% \mathrm{CI}) \\
\text { DOR }(95 \% \mathrm{CI}) \\
\text { AUC }\end{array}$ & - & - & - & - & - \\
\hline
\end{tabular}

years, many systematic reviews and/or meta-analyses focusing on and analysing the diagnostic accuracy of these methods were undertaken (e.g. Refs. 13 and 17-23). In comparison to all previous work, the present systematic review and meta-analysis provide an overview and comparison between commonly used diagnostic test methods for proximal caries detection on the basis of the available literature from in vitro and in vivo caries diagnostic studies. Another unique feature of this work is that the spectrum of heterogeneity was narrowed due to the inclusion of a tailor-made RoB analysis, which resulted in the inclusion of studies with a low to moderate RoB.

When discussing the results from the systematic search of the literature, it is noteworthy that, first, the final number of selected studies was low and, second, that clinical trials $(N=5)$ were rare in comparison to laboratory studies $(N=31$, Fig. 1, Tables 2 and 3$)$. With respect to this imbalance, there seems to be an urgent need to design, plan, 
and conduct well-designed and highly standardised clinical diagnostic studies that compare different test methods in a well-justified and homogenous patient sample. Problematically, the clinical validation of the caries extent, cavity level, or activity by reference tests cannot be performed in full due to the unavailability of reference test methods for evaluating caries activity and the impossibility of applying histological methods under clinical conditions. This explains the documented imbalance, limits the planning of future clinical trials, and, considering the importance of clinical testing, also illustrates the need to develop clinically applicable reference standards, which may improve the present situation in the future.

Regarding the meta-analytic diagnostic performance of all the included diagnostic methods and used cutoff levels, it needs to be highlighted that, first, in some of the categories, only one and, at best, a few studies were identified (Tables 2 and 3). Second, several studies included only a small number of investigated teeth (Supplementary Tables S3g, h, S4g, h, $\mathrm{S} 5 \mathrm{~g}, \mathrm{~h}, \mathrm{~S} 6 \mathrm{~g}$, and $\mathrm{h}$ ). Third, the proportions of included teeth in relation to the caries spectrum were often misbalanced. Therefore, the results from this meta-analysis (Table 3) should not be overrated and generalised. Nevertheless, some aspects of the meta-analysis need to be discussed. Under in vitro conditions, all test methods showed mostly high SP values, while SE varied between the different methods and thresholds. A substantial difference between SE values was registered for VE under in vitro and in vivo conditions (Table 3), which was also reported by Gimenez et al. [18]. This finding is most likely related to the simple fact that clinical caries detection is more difficult to perform due to the limited direct view of proximal surfaces that could not be simulated in full under laboratory conditions. Here, VE under in vitro conditions probably provides more details, which results in higher SE values, with exception of results for dentin detection level based on just one study. This methodological aspect illustrates the difficulty of comparing data from clinical and in vitro investigations. Therefore, the results from any study need to be interpreted with consideration of the methodology of the corresponding trial.

For proximal caries detection and diagnostics, the BWR is the most frequently used additional method [14]. Therefore, it is not surprising that the majority of included studies investigated conventional and/or digital BWR. Thus, to eliminate possible bias originating from the use of different conventional film types, the available speed classes (D-, E-, and F-speed) were analysed separately. Similarly, studies on digital BWR that used sensor or phosphor plate imaging technology were also assessed separately, which is in contrast to a previously published systematic review that merged all these data into one category [13]. The results (Table 3) revealed high SP and low SE for all types of BWR except for phosphor plate-based systems. This ratio needs to be discussed, again, in relation to the included spectrum of caries lesions in the corresponding studies. Here, frequently, the proportion of dentin caries lesions was low. In contrast, when it was only possible to sample dentin caries lesions in a clinical investigation [67], the SE was mostly documented as good. This example highlights the influence of the sample constitution on diagnostic performance.

LF has been increasingly used as an additional caries detection aid [15] and has also been included in several diagnostic studies on proximal sites. The results found high AUC, SE, and SP values for LF, which is in line with earlier findings from Gimenez et al. [17]. Contrary to these encouraging results, clinical usage is sensitive, and good standardisation is essential to avoid false-positive readings due to other fluorescence sources [20].

This systematic review and meta-analysis have strengths and limitations from a methodological point of view. As for strengths, first, all diagnostic methods for proximal caries detection and diagnostics were merged into one metaanalysis. Second, the study selection followed a strict protocol and included only those studies with a low RoB in core categories. On the one hand, this procedure resulted in the selection of studies with a comparable methodology and good quality; on the other hand, it caused a substantial reduction in includable scientific reports. Another strength of this project seems to be the detailed and extensive documentation (Supplemental online content). As it is necessary to mention limitations, in many categories, no or only a few studies were available, which limits the generalisability of the meta-analytical results. Another potential limitation is the quality assessment of all studies that basically met the inclusion criteria. Here, extensive discussions were held in the study group regarding the question "Which indicators in the reporting are linked to which degree of bias?" It is possible that some of our decisions could be questioned, especially concerning studies with weak methodological reporting. Another limitation might be that variables, e.g. sample size, sample composition, sample storage, study setting, or examiner experience, which could possibly influence or confound the results of the meta-analysis remained unconsidered. This might be another reason not to overrate the findings from this meta-analysis.

\section{Conclusion}

When considering the available data records and quality in relation to the consequences for future research, it must be concluded that there is an overall need for high-quality, well-designed, and well-powered caries detection and diagnostic studies. This need must be emphasised much more for clinical data. Another urgent void that has to be addressed is the non-availability of an acceptable reference standard for 
clinical caries detection and diagnostic studies. Here, experts should try to reach a consensus regarding which procedure will meet ethical and methodological requirements.

Supplementary Information The online version contains supplementary material available at https://doi.org/10.1007/s00784-021-04113-1.

Funding Open Access funding enabled and organized by Projekt DEAL. This project was funded by a grant for creating a scientific network obtained from the German Research Foundation (Deutsche Forschungsgemeinschaft, SCHU-3217/1-1).

\section{Declarations}

Ethics approval This article does not contain any animal or human studies performed by any of the authors. All applicable international, national, and/or institutional recommendations for conducting systematic revisions were followed.

Informed consent For this type of study, formal consent is not required.

Conflict of interest The authors declare no competing interests.

Open Access This article is licensed under a Creative Commons Attribution 4.0 International License, which permits use, sharing, adaptation, distribution and reproduction in any medium or format, as long as you give appropriate credit to the original author(s) and the source, provide a link to the Creative Commons licence, and indicate if changes were made. The images or other third party material in this article are included in the article's Creative Commons licence, unless indicated otherwise in a credit line to the material. If material is not included in the article's Creative Commons licence and your intended use is not permitted by statutory regulation or exceeds the permitted use, you will need to obtain permission directly from the copyright holder. To view a copy of this licence, visit http://creativecommons.org/licenses/by/4.0/.

\section{References}

1. Splieth CH, Santamaria RM, Basner R, Schuler E, Schmoeckel J (2019) 40-year longitudinal caries development in German adolescents in the light of new caries measures. Caries Res 53(6):609-616

2. Marthaler TM (2004) Changes in dental caries 1953-2003. Caries Res 38(3):173-181

3. Pretty IA, Ekstrand KR (2016) Detection and monitoring of early caries lesions: a review. Eur Arch Paediatr Dent 17(1):13-25

4. Pitts N (2009) Detection, assessment, diagnosis and monitoring of caries, vol 21. Karger, Basel

5. Kühnisch J, Ekstrand KR, Pretty I, Twetman S, van Loveren C, Gizani S, SpyridonosLoizidou M (2016) Best clinical practice guidance for management of early caries lesions in children and young adults: an EAPD policy document. Eur Arch Paediatr Dent 17(1):3-12

6. Schwendicke F, Splieth C, Breschi L, Banerjee A, Fontana M, Paris S, Burrow MF, Crombie F, Page LF, Gaton-Hernandez P, Giacaman R, Gugnani N, Hickel R, Jordan RA, Leal S, Lo E, Tassery H, Thomson WM, Manton DJ (2019) When to intervene in the caries process? An expert Delphi consensus statement. Clin Oral Investig 23(10):3691-3703

7. Pretty IA (2006) Caries detection and diagnosis: novel technologies. J Dent 34(10):727-739
8. Hopcraft MS, Morgan MV (2005) Comparison of radiographic and clinical diagnosis of approximal and occlusal dental caries in a young adult population. Community Dent Oral Epidemiol 33(3):212-218

9. Poorterman JH, Aartman IH, Kalsbeek H (1999) Underestimation of the prevalence of approximal caries and inadequate restorations in a clinical epidemiological study. Community Dent Oral Epidemiol 27(5):331-337

10. Poorterman JH, Aartman IH, Kieft JA, Kalsbeek H (2000) Value of bite-wing radiographs in a clinical epidemiological study and their effect on the DMFS index. Caries Res 34(2):159-163

11. Poorterman JH, Weerheijm KL, Groen HJ, Kalsbeek H (2000) Clinical and radiographic judgement of occlusal caries in adolescents. Eur J Oral Sci 108(2):93-98

12. Raper HR (1925) Practical clinical preventive dentistry based upon periodic Roentgen-ray examinations. J Am Dent Assoc 12(9):1084-1100

13. Schwendicke F, Tzschoppe M, Paris S (2015) Radiographic caries detection: a systematic review and meta-analysis. J Dent 43(8):924-933

14. Neuhaus KW, Ellwood R, Lussi A, Pitts NB (2009) Traditional lesion detection aids. Monogr Oral Sci 21:42-51

15. Neuhaus KW, Longbottom C, Ellwood R, Lussi A (2009) Novel lesion detection aids. Monogr Oral Sci 21:52-62

16. Twetman S, Axelsson S, Dahlen G, Espelid I, Mejare I, Norlund A, Tranaeus S (2013) Adjunct methods for caries detection: a systematic review of literature. Acta Odontol Scand 71(3-4):388-397

17. Gimenez T, Braga MM, Raggio DP, Deery C, Ricketts DN, Mendes FM (2013) Fluorescence-based methods for detecting caries lesions: systematic review, meta-analysis and sources of heterogeneity. PLoS One 84:e60421

18. Gimenez T, Piovesan C, Braga MM, Raggio DP, Deery C, Ricketts DN, Ekstrand KR, Mendes FM (2015) Visual inspection for caries detection: a systematic review and meta-analysis. J Dent Res 94(7):895-904

19. Gimenez T, Piovesan C, Braga MM, Raggio DP, Deery C, Ricketts DN, Ekstrand KR, Mendes FM (2015) Clinical relevance of studies on the accuracy of visual inspection for detecting caries lesions: a systematic review. Caries Res 49(2):91-98

20. Bader JD, Shugars DA (2004) A systematic review of the performance of a laser fluorescence device for detecting caries. J Am Dent Assoc 135(10):1413-1426

21. Bader JD, Shugars DA, Bonito AJ (2001) Systematic reviews of selected dental caries diagnostic and management methods. J Dent Educ 65(10):960-968

22. Bader JD, Shugars DA, Bonito AJ (2002) A systematic review of the performance of methods for identifying carious lesions. J Public Health Dent 62(4):201-213

23. Ekstrand KR, Gimenez T, Ferreira FR, Mendes FM, Braga MM (2018) The International Caries Detection and Assessment System - ICDAS: a systematic review. Caries Res 52(5):406-419

24. McInnes MDF, Moher D, Thombs BD, McGrath TA, Bossuyt PM, Clifford T, Cohen JF, Deeks JJ, Gatsonis C, Hooft L, Hunt HA, Hyde CJ, Korevaar DA, Leeflang MMG, Macaskill P, Reitsma JB, Rodin R, Rutjes AWS, Salameh JP, Stevens A, Takwoingi Y, Tonelli M, Weeks L, Whiting P, Willis BH (2018) Preferred reporting items for a systematic review and meta-analysis of diagnostic test accuracy studies: the PRISMA-DTA statement. JAMA 319(4):388-396

25. Macaskill P, Gatsonis C, Deeks JJ, Harbord RM, Takwoingi Y (2010) Chapter10: Analysing and Presenting Results. In: Deeks JJ, Bossuyt PM, Gatsonis C (editors), Cochrane Handbook for Systematic Reviews of Diagnostic Test Accuracy Version 1.0. The Cochrane Collaboration. Available from: https://www.srdta.cochr ane.org/. 
26 Peters M, Godfrey C, McInerney P, Baldini SC, Khalil H, Parker D (2015) The Joanna Briggs Institute Reviewers' Manual 2015: methodology for JBI scoping reviews. The Joanna Briggs Institute, Adelaide, SA Australia

27. Campbell JM, Klugar M, Ding S, Carmody DP, Hakonsen SJ, Jadotte YT, White S, Munn Z (2015) Diagnostic test accuracy: methods for systematic review and meta-analysis. Int J Evid Based Healthc 13(3):154-162

28. Doebler P (2019) mada: Meta-analysis of diagnostic accuracy. $R$ package version 0.5.9. Available from: https://CRAN.R-project. org/package $=$ mada. Date Accessed: 31.12.2019.

29. RStudio Team (2018). RStudio: Integrated Development for R. RStudio I, Boston, MA Available from: http://www.rstudio.com/. Date Accessed: 31.12.2019.

30. Reitsma JB, Glas AS, Rutjes AW, Scholten RJ, Bossuyt PM, Zwinderman AH (2005) Bivariate analysis of sensitivity and specificity produces informative summary measures in diagnostic reviews. J Clin Epidemiol 58(10):982-990

31. Chu H, Guo H, Zhou Y (2010) Bivariate random effects metaanalysis of diagnostic studies using generalized linear mixed models. Med Decis Making 30(4):499-508

32. DerSimonian R, Laird N (1986) Meta-analysis in clinical trials. Control Clin Trials 7(3):177-188

33. Bossuyt P DC, Deeks, J, Hyde C, Leeflang M, Scholten R (2013) Interpreting results and drawing conclusions. In: Deeks JJ, Bossuyt PM, Gatsonis C (eds) Cochrane Handbook for Systematic Reviews of Diagnostic Test Accuracy Version 1.0. The Cochrane Collaboration. Available from: http://srdta.cochrane.org/. Date Accessed: 31.12.2019

34. Macaskill P GC, Deeks JJ, Harbord RM, Takwoingi Y (2010) Chapter 10: analysing and presenting results. In: Deeks JJ, Bossuyt PM, Gatsonis C (eds) Cochrane handbook for systematic reviews of diagnostic test accuracy version 1.0. The Cochrane Collaboration. Available from: http://srdta.cochrane.org/. Date Accessed: 31.12.2019

35. Abesi F, Mirshekar A, Moudi E, Seyedmajidi M, Haghanifar S, Haghighat N, Bijani A (2012) Diagnostic accuracy of digital and conventional radiography in the detection of non-cavitated approximal dental caries. Iran J Radiol 9(1):17-21

36. Abogazalah N, Eckert GJ, Ando M (2019) In vitro visual and visible light transillumination methods for detection of natural noncavitated approximal caries. Clin Oral Investig 23(3):1287-1294

37. Astvaldsdottir A, Ahlund K, Holbrook WP, de Verdier B, Tranaeus S (2012) Approximal caries detection by DIFOTI: in vitro comparison of diagnostic accuracy/efficacy with film and digital radiography. Int J Dent 2012:326401

38. Behere R, Lele S (2011) Reliability of Logicon caries detector in the detection and depth assessment of dental caries: an in-vitro study. Indian J Dent Res 22(2):362

39. da Silva Neto JM, dos Santos RL, Sampaio MC, Sampaio FC, Passos IA (2008) Radiographic diagnosis of incipient proximal caries: an ex-vivo study. Braz Dent J 19(2):97-102

40. de Souza JF, Diniz MB, Boldieri T, Rodrigues JA, Lussi A, de Cassia Loiola Cordeiro R, (2014) In vitro performance of a pen-type laser fluorescence device and bitewing radiographs for approximal caries detection in permanent and primary teeth. Indian J Dent Res 25(6):702-710

41. Ekstrand KR, Luna LE, Promisiero L, Cortes A, Cuevas S, Reyes JF, Torres CE, Martignon S (2011) The reliability and accuracy of two methods for proximal caries detection and depth on directly visible proximal surfaces: an in vitro study. Caries Res 45(2):93-99

42. Forner-Navarro L, Puy Ma CL, Godoy FG (2008) Diagnostic performance of radiovisiography in combination with a diagnosis assisting program versus conventional radiography and radiovisiography in basic mode and with magnification. Med Oral, Patol Oral Cirugia Bucal 13(4):261-265

43. Haak R, Wicht MJ, Nowak G, Hellmich M (2003) Influence of displayed image size on radiographic detection of approximal caries. Dentomaxillofac Radiol 32(4):242-246

44 Hintze H, Wenzel A (2003) Diagnostic outcome of methods frequently used for caries validation. A comparison of clinical examination, radiography and histology following hemisectioning and serial tooth sectioning. Caries Res 37(2):115-124

45. Isidor S, Faaborg-Andersen M, Hintze H, Kirkevang LL, Frydenberg M, Haiter-Neto F, Wenzel A (2009) Effect of monitor display on detection of approximal caries lesions in digital radiographs. Dentomaxillofacial Radiol 38(8):537-541

46. Jan J, Wan Bakar WZ, Mathews SM, Okoye LO, Ehler BR, Louden C, Amaechi BT (2016) Proximal caries lesion detection using the Canary Caries Detection System: an in vitro study. J Investig Clin Dent 7(4):383-390

47. Lussi A, Hack A, Hug I, Heckenberger H, Megert B, Stich H (2006) Detection of approximal caries with a new laser fluorescence device. Caries Res 40(2):97-103

48 Matalon S, Feuerstein O, Kaffe I (2003) Diagnosis of approximal caries: bite-wing radiology versus the Ultrasound Caries Detector. An in vitro study. Oral Surg Oral Med Oral Pathol Oral Radiol Endod 95(5):626-631

49. Mitropoulos P, Rahiotis C, Stamatakis H, Kakaboura A (2010) Diagnostic performance of the visual caries classification system ICDAS II versus radiography and micro-computed tomography for proximal caries detection: an in vitro study. J Dent 38(11):859-867

50. Neuhaus KW, Ciucchi P, Rodrigues JA, Hug I, Emerich M, Lussi A (2015) Diagnostic performance of a new red light LED device for approximal caries detection. Lasers Med Sci 30(5):1443-1447

51. Pontual AA, De Melo DP, De Almeida SM, Boscolo FN, Haiter Neto F (2010) Comparison of digital systems and conventional dental film for the detection of approximal enamel caries. Dentomaxillofacial Radiol 39(7):431-436

52. Ricketts DN, Whaites EJ, Kidd EA, Brown JE, Wilson RF (1997) An evaluation of the diagnostic yield from bitewing radiographs of small approximal and occlusal carious lesions in a low prevalence sample in vitro using different film types and speeds. $\mathrm{Br}$ Dent J 182(2):51-58

53. Rockenbach MI, Veeck EB, da Costa NP (2008) Detection of proximal caries in conventional and digital radiographs: an in vitro study. Stomatologija 10(4):115-120

54. Senel B, Kamburoglu K, Ucok O, Yuksel SP, Ozen T, Avsever H (2010) Diagnostic accuracy of different imaging modalities in detection of proximal caries. Dentomaxillofacial Radiol 39(8):501-511

55. Tonkaboni A, Saffarpour A, Aghapourzangeneh F, Fard MJK (2019) Comparison of diagnostic effects of infrared imaging and bitewing radiography in proximal caries of permanent teeth. Lasers Med Sci 34(5):873-879

56. Vivek V, Thomas S, Nair BJ, Vineet AD, Thomas J, Ranimol P, Vijayan AK (2015) Comparison of diagnostic ability of storage phosphor plate in detecting proximal caries with direct measurement by stereomicroscope: a pilot study. Clin Pract 5(3):763

57. Wenzel A, Hintze H, Kold LM, Kold S (2002) Accuracy of computer-automated caries detection in digital radiographs compared with human observers. Eur J Oral Sci 110(3):199-203

58. Wenzel A, Haiter-Neto F, Gotfredsen E (2007) Risk factors for a false positive test outcome in diagnosis of caries in approximal surfaces: impact of radiographic modality and observer characteristics. Caries Res 41(3):170-176

59. Bozdemir E, Aktan AM, Ozsevik A, SirinKararslan E, Ciftci ME, Cebe MA (2016) Comparison of different caries detectors for approximal caries detection. J Dent Sci 11(3):293-298 
60. Safi Y, Shamloo Mahmoudi N, Aghdasi MM, Eslami Manouchehri M, Rahimian R, Valizadeh S, Vasegh Z, Azizi Z (2015) Diagnostic accuracy of cone beam computed tomography, conventional and digital radiographs in detecting interproximal caries. J Med Life 8(Spec Iss 3):77-82

61. Zangooei Booshehry M, Davari A, Ezoddini Ardakani F, Rashidi Nejad MR (2010) Efficacy of application of pseudocolor filters in the detection of interproximal caries. J Dent Res Dent Clin Dent Prospects 4(3):79-82

62. Haiter-Neto F, Spinelli Casanova M, Frydenberg M, Wenzel A (2009) Task-specific enhancement filters in storage phosphor images from the VistaScan system for detection of proximal caries lesions of known size. Oral Surg Oral Med Oral Pathol Oral Radiol Endodontol 107(1):116-121

63. Wenzel A, Haiter-Neto F, Gotfredsen E (2007) Influence of spatial resolution and bit depth on detection of small caries lesions with digital receptors. Oral Surg Oral Med Oral Pathol Oral Radiol Endodontol 103(3):418-422

64. Ariji Y, Takahashi JI, Matsui O, Okano T, Naitoh M, Yuasa H, Iida H, Hasegawa J, Senda A, Ariji E (1998) In vitro comparison of subjective image quality of the Pana Digital intraoral x-ray imaging system and conventional intraoral radiography in caries detection. Oral Radiol 14(2):75-83

65. Zayet MK, Helaly YR, Eiid SB (2014) Effect of changing the kilovoltage peak on radiographic caries assessment in digital and conventional radiography. Imaging Sci Dent 44(3):199-205
66. Ozkan G, Guzel KGU (2017) Clinical evaluation of near-infrared light transillumination in approximal dentin caries detection. Lasers Med Sci 32(6):1417-1422

67. Kühnisch J, Söchtig F, Pitchika V, Laubender R, Neuhaus KW, Lussi A, Hickel R (2016) In vivo validation of near-infrared light transillumination for interproximal dentin caries detection. Clin Oral Investig 20(4):821-829

68. Menem R, Barngkgei I, Beiruti N, Al Haffar I, Joury E (2017) The diagnostic accuracy of a laser fluorescence device and digital radiography in detecting approximal caries lesions in posterior permanent teeth: an in vivo study. Lasers Med Sci 32(3):621-628

69. Huth KC, Lussi A, Gygax M, Thum M, Crispin A, Paschos E, Hickel R, Neuhaus KW (2010) In vivo performance of a laser fluorescence device for the approximal detection of caries in permanent molars. J Dent 38(12):1019-1026

70. Shimada Y, Nakagawa H, Sadr A, Wada I, Nakajima M, Nikaido T, Otsuki M, Tagami J, Sumi Y (2014) Noninvasive crosssectional imaging of proximal caries using swept-source optical coherence tomography (SS-OCT) in vivo. J Biophotonics 7(7):506-513

Publisher's note Springer Nature remains neutral with regard to jurisdictional claims in published maps and institutional affiliations.

\section{Authors and Affiliations}

\section{Mila Janjic Rankovic ${ }^{1}$. Svetlana Kapor ${ }^{2}$ - Yegane Khazaei ${ }^{2,3}$ • Alexander Crispin ${ }^{3}$. Ina Schüler ${ }^{4}$. Felix Krause ${ }^{5}$. Kim Ekstrand ${ }^{6} \cdot$ Stavroula Michou $^{6} \cdot$ Florin Eggmann $^{7}$. Adrian Lussi ${ }^{8,9} \cdot$ Marie-Charlotte Huysmans $^{10}$. Klaus Neuhaus ${ }^{7,11}$. Jan Kühnisch ${ }^{2,12}$}

1 Department of Orthodontics and Dentofacial Orthopedics, University Hospital, Ludwig-Maximilians University Munich, Munich, Germany

2 Department of Conservative Dentistry and Periodontology, University Hospital, Ludwig-Maximilians University Munich, Munich, Germany

3 Institute of Medical Biometry and Epidemiology, Ludwig-Maximilians University of Munich, Munich, Germany

4 Department of Orthodontics, Section of Preventive and Paediatric Dentistry, University Hospital, Jena, Germany

5 Clinic for Operative Dentistry, Periodontology and Preventive Dentistry, University Hospital RWTH Aachen, Aachen, Germany

6 Department of Odontology, University of Copenhagen, Copenhagen, Denmark
7 Clinic of Periodontology, Endodontology and Cariology, University Centre for Dental Medicine Basel, University of Basel, Basel, Switzerland

8 Department of Operative Dentistry and Periodontology, Faculty of Dentistry, University Medical Centre, Freiburg, Germany

9 School of Dental Medicine, University of Bern, Bern, Switzerland

10 Department of Dentistry, Radboud University Medical Centre, Nijmegen, The Netherlands

11 Department of Dermatology, Inselspital - Bern University Hospital, Bern, Switzerland

12 Poliklinik für Zahnerhaltung und Parodontologie, Klinikum der Universität München, LMU München, Goethestraße 70, 80336 Munich, Germany 